\title{
Application of the dual-luciferase reporter assay to the analysis of promoter activity in Zebrafish embryos

\author{
Francisca Alcaraz-Pérez ${ }^{1,2}$, Victoriano Mulero*2 and María L Cayuela*1
}

Address: ${ }^{1}$ Research Unit, Department of Surgery, University Hospital "Virgen de la Arrixaca", 30120 Murcia, Spain and ${ }^{2}$ Department of Cell Biology and Histology, Faculty of Biology, University of Murcia, 30100 Murcia. Spain

Email: Francisca Alcaraz-Pérez - palcaraz@um.es; Victoriano Mulero* - vmulero@um.es; María L Cayuela* - marial.cayuela@carm.es

* Corresponding authors

Published: 27 October 2008

BMC Biotechnology 2008, 8:81 doi:10.1/86/1472-6750-8-8I

This article is available from: http://www.biomedcentral.com/I472-6750/8/8I

(C) 2008 Alcaraz-Pérez et al; licensee BioMed Central Ltd.

This is an Open Access article distributed under the terms of the Creative Commons Attribution License (http://creativecommons.org/licenses/by/2.0), which permits unrestricted use, distribution, and reproduction in any medium, provided the original work is properly cited.
Received: 8 July 2008

Accepted: 27 October 2008

\begin{abstract}
Background: The dual-luciferase assay has been widely used in cell lines to determine rapidly but accurately the activity of a given promoter. Although this strategy has proved very useful, it does not allow the promoter and gene function to be analyzed in the context of the whole organism.

Results: Here, we present a rapid and sensitive assay based on the classical dual-luciferase reporter technique which can be used as a new tool to characterize the minimum promoter region of a gene as well as the in vivo response of inducible promoters to different stimuli. We illustrate the usefulness of this system for studying both constitutive (telomerase) and inducible (NF-KBdependent) promoters. The flexibility of this assay is demonstrated by induction of the NF-KBdependent promoters using simultaneous microinjection of different pathogen-associated molecular patterns as well as with the use of morpholino-gene mediated knockdown.

Conclusion: This assay has several advantages compared with the classical in vitro (cell lines) and in vivo (transgenic mice) approaches. Among others, the assay allows a rapid and quantitative measurement of the effects of particular genes or drugs in a given promoter in the context of a whole organism and it can also be used in high throughput screening experiments.
\end{abstract}

\section{Background}

The zebrafish has been established as an excellent model for studying any biological process. This organism possesses many advantages including ease of experimentation, optical clarity, drug administration, amenability to in vivo manipulation and feasibility of reverse and forward genetic approaches. The fish reach sexual maturity in only 3 to 4 months, and adult females are capable of producing 100 to 200 eggs weekly. Many thousands of animals can be kept in a fish facility requiring much less space than mice or other mammals, and hence the zebrafish is regarded as a cost-effective experimental vertebrate model for large-scale genetic screening [1]. Furthermore, the high degree of homology between the zebrafish genome and that of humans makes such discoveries especially pertinent to human disease and development $[2,3]$.

Morpholino antisense oligonucleotides $(\mathrm{MO})$ have been widely used to inhibit gene function in zebrafish embryos [4-7] and are usually used as sequence-specific translation-blocking or splicing-blocking agents. Recently, a quantitative assessment of the knockdown efficiency of morpholinos has been performed in zebrafish embryos and its effectiveness proved [8]. Furthermore, microinjection of DNA constructs into single-cell fertilized zebrafish embryos has also proven successful in the generation of 
transgenic zebrafish. The widespread use of fluorescent proteins in mammalian systems has been successfully adapted for use in zebrafish, which are well-suited to the use of fluorescence because of their optical clarity and external development. By linking a fluorescent protein such as enhanced green fluorescent protein (eGFP) or Discosoma sp. red fluorescent protein (DsRed) to a gene or promoter of interest, expression can be easily visualized in living animals [9].

The dual luciferase assay has been widely used in cell lines to determine rapidly and accurately the activity of a given promoter. Although this strategy has been very useful, it does not allow analysis of the promoter and gene function in the context of the whole organism. To overcome these limitations, we have developed a protocol based on the dual luciferase system in zebrafish embryos. We illustrate the usefulness of this system for studying the promoter of telomerase, a key enzyme in the fields of cancer, stem cells and aging [10], and a NF- $\kappa \mathrm{B}$-dependent promoter, a master regulator of the immune response [11]. The luciferase reporter DNA plasmids were injected into zebrafish embryos at the one-cell developmental stage, together with $\mathrm{MO}$ or the expression constructs of interest, and the luciferase activity was determined in the time frame of MO activity (24-48 h later). In addition, the flexibility of this assay is also illustrated by activation of the NF-кBdependent promoters by simultaneous microinjection of different pathogen-associated molecular patterns (PAMPs).

The protocol presented here provides details of how to apply the dual-luciferase assay to determining the activity of constitutive and inducible promoters in zebrafish embryos. This approach involves three steps: (1) cloning the promoter of interest in the firefly luciferase reporter construct, (2) microinjecting the embryos with this construct together with the appropriate Renilla luciferase reporter and (3) measuring the promoter activity with the dual luciferase system in whole embryo extracts.

\section{Results}

The protocol presented here should result in very sensitive and accurate measurement of promoter activity and analysis of gene function in the context of the whole organism, which represents an important advantage over traditional measurement in cell lines. We first illustrated the usefulness of our protocol to analyze the promoter activity of zebrafish telomerase-reverse transcriptase (zfTERT) (Fig. 1). At $24 \mathrm{~h}$ post-injection (hpi), the $3 \mathrm{~Kb}$ fragment upstream of the zfTERT coding sequence was able to drive the expression of the firefly luciferase reporter while the 1 $\mathrm{Kb}$ fragment failed to significantly increased the basal expression. Therefore, the relative promoter activity of each fragment could be quantitatively determined.

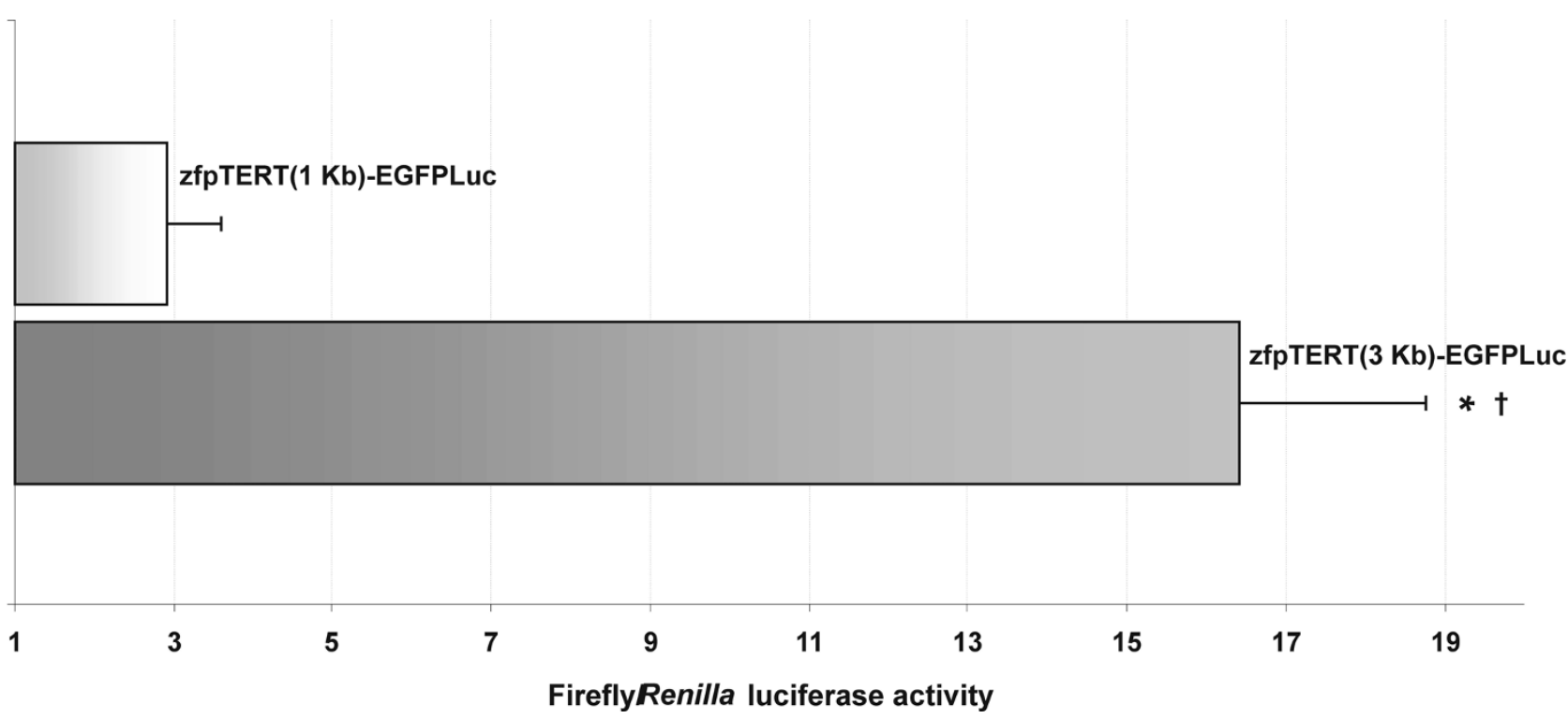

Figure I

Analysis of zfTERT promoter activity in whole zebrafish embryos. Zebrafish one to eight-cell embryos were microinjected with plessEGFPLuc, zfpTERT(I Kb)-EGFPLuc or zfpTERT(3 Kb)-EGFPLuc and the pRL-CMV (I0:I) reporter vectors. Twenty-four hours after microinjection, the firefly and Renilla luciferase activity was measured using the Dual-Luciferase Reporter Assay System. The results are expressed as the mean \pm S.E. of normalized luciferase activity relative to plessEGFPLuc injected embryos. ${ }^{*} p<0.05$ vs. plessEGFPLuc. ${ }^{\dagger} p<0.05$ vs. zfpTERT(I Kb)-EGFPLuc. 
The critical step in the protocol presented here is the correct choice of the promoter used for normalization. The cytomegalovirus (CMV) immediate-early promoter is a strong promoter used for both the in vitro and in vivo expression of proteins in signal transduction and gene therapy studies. However, CMV activity is induced by external stimuli such as endotoxin from Gram-negative bacteria (lipopolysaccharide, LPS), cytokines and phorbol esters [12]. Therefore, for the study of NF- $\kappa \mathrm{B}$ activation, we first have studied the effects of bacterial LPS and DNA in the expression of several Renilla luciferase reporter constructs. Among the four candidates tested, the CMV promoter was strongly induced by both PAMPs, i.e. Escherichia coli LPS (EcLPS) and Vibrio anguillarum DNA ( $V a \mathrm{DNA})$, whereas the translation elongation factor EF1 $\alpha$ promoter was inhibited by EcLPS and, to some extent, by $\mathrm{VaDNA}$. In contrast, the herpes simplex virus thymidine kinase (TK) promoter and the early SV40 enhancer/promoter region showed a more constant expression (Fig. 2A and $2 \mathrm{~B}$ ) and were therefore selected for further studies. Figure $2 \mathrm{C}$ illustrates the profound effects of the plasmid used for normalization in the measurement of the induction of NF- $\kappa \mathrm{B}$. When using EcLPS, a 29 vs. 14 fold induction of NF- $\kappa \mathrm{B}$ activity was obtained with the TK and the $\mathrm{CMV}$ promoters, respectively (Fig. 2C), indicating that induction of CMV by EcLPS resulted in the underestimation of the NF- $\kappa \mathrm{B}$ activation by this PAMP. Similarly, 21 vs. 738 fold induction of NF- $\mathrm{B}$ was observed with VaDNA when using the SV40 and the TK promoters, respectively (Fig. 2C), indicating that the inhibition of the TK promoter by $\mathrm{VaDNA}$ resulted in the overestimation of the NF- $\mathrm{NB}$ induced by this PAMP.

We finally validated the usefulness of this technique for studying a gene of interest by using MO-gene mediated knockdown. Figure 3 illustrates an example of the inhibition of the NF- $\kappa \mathrm{B}$ activation triggered by $\mathrm{VaDNA}$ using a translation-blocking MO against MyD88 [13], an adaptor protein involved in the downstream signalling following the engagement of bacterial DNA by its cognate receptor (TLR9) [14]. The results showed that injection of the MO against MyD88 resulted in a significant inhibition (> $30 \%$ ) of the NF- $\kappa \mathrm{B}$ activation induced by bacterial DNA, while injection of a MO directed against TLR3, which is involved in the recognition of double-stranded RNA [15], failed to affect the NF- $\kappa \mathrm{B}$ activation induced by bacterial DNA (Fig. 3).

\section{Discussion}

The protocol presented here provides details of how to apply the dual-luciferase assay to determining the activity of both constitutive and inducible promoters in zebrafish embryos. Beyond genetics and experimental tools, the strength of the zebrafish resides in the analysis of phenotype [1]. Perhaps no other organism (and certainly no ver- tebrate) is better suited to high-throughput phenotyping. The scale that can be achieved in zebrafish experiments is impressive by vertebrate standards. Early zebrafish embryos are less than $1 \mathrm{~mm}$ in diameter, allowing several embryos to fit easily in a single well of a 384-well plate. Whole organisms offer several advantages over cell lines for forward chemical genetic screens, providing information on tissue specificity, toxicity and accounting for bioavailability. Furthermore, cells are not transformed and are in their normal physiological milieu of cell-cell and cell-extracellular matrix interactions [16-18]. Use of the whole organism can also allow the screening of processes that are not easily replicated in vitro such as organ development. The advantages of zebrafish screening over invertebrate model organisms are their closer evolutionary relationship to humans [16-18]. Therefore, the assay described here represents a promising route to the identification and validation of novel drug targets. Analysis of the promoter of newly identified genes that underlie zebrafish disease phenotypes might lead directly to the identification of novel drug targets or genes that can correct the phenotype.

Because zebrafish development occurs ex uterus and they have a large number of offspring, hundreds or thousands of embryos can be injected per day and the results of this assay can be obtained within 24-48 h, although shorter time points can also be analyzed if either the mRNA coding for the gene under study or the recombinant protein are used. Although some variation was found between replicates, these can be easily avoided by the high number of technical replicates achievable. The high-fold induction of luciferase activity, together with barely detectable levels of basal expression, makes it an ideal system for the in vivo analysis of inducible promoters. In addition, the assay can be combined with powerful MO-gene mediated knockdown or gene over-expression to rapidly determine the functions of a particular gene (1-2 days compared with months-years needed for the generation of knockout mice). Therefore, this technique appears to be suitable for studying the activity and responses of different promoters and gene functions as well as for the validation of genetic constructs. However, this technique does not provide spatial information on gene expression and, therefore, it might be useful as a complementary technique to in situ hybridization and fluorescent microscopy. To avoid this limitation, all our promoters drive the expression of a fusion of eGFP and firefly luciferase, which might allow the simultaneous determination of the expression levels and the spatial localization of the promoter under analysis.

A shortcoming of the present assay, however, is the transient expression of the constructs and, therefore, only short-term responses of promoters can be studied. For 


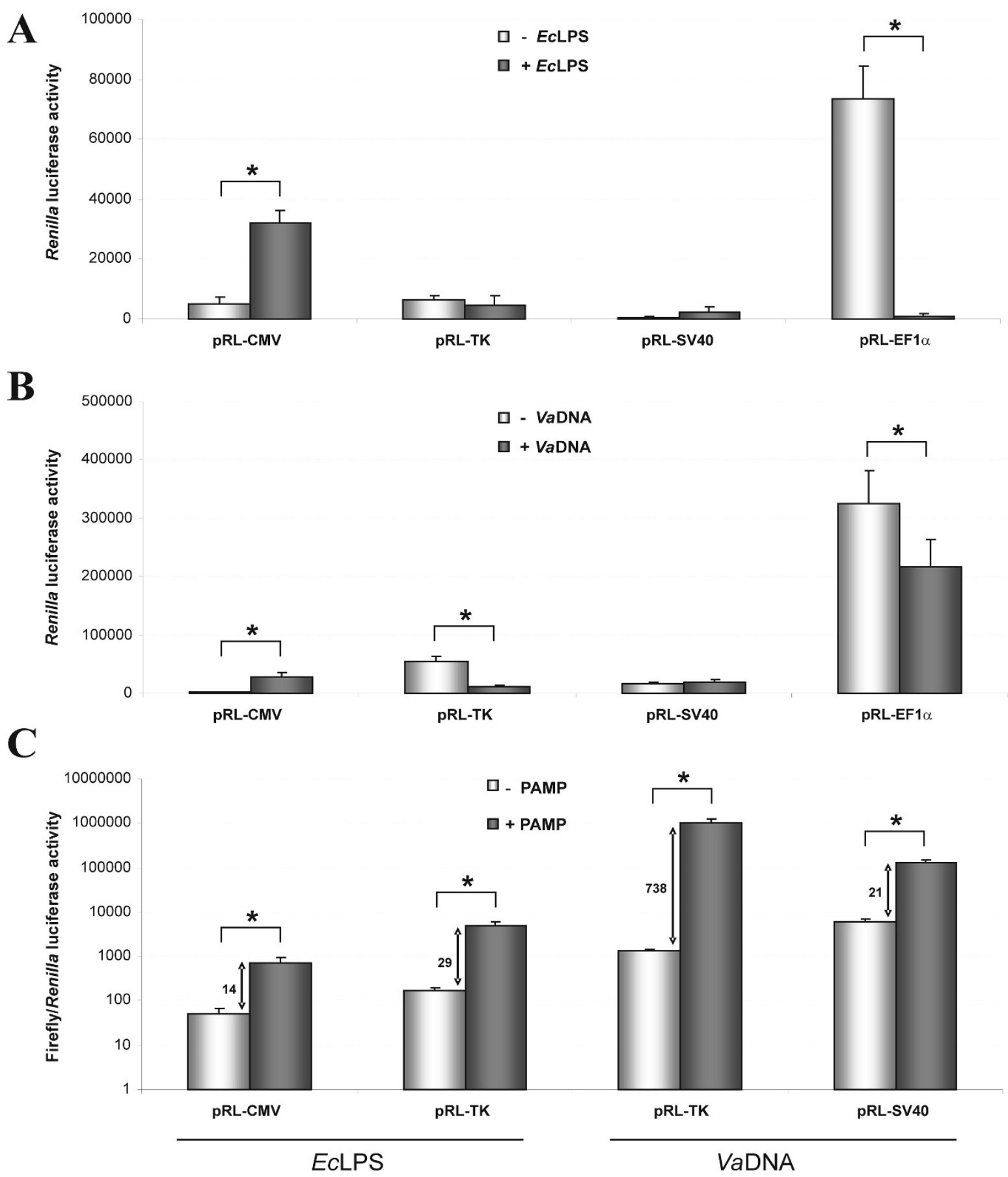

Figure 2

Optimization of the different Renilla luciferase reporter constructs. Zebrafish one to eight-cell embryos were microinjected with $30 \mathrm{ng}$ EcLPS $(\mathbf{A}, \mathbf{C})$ or $6.5 \mathrm{ng} \operatorname{VaDNA}(\mathbf{B}, \mathbf{C})$ and NF- $\kappa$ B::Luc together with the pRL-CMV, pRL-TK, pRL-SV40 or $\mathrm{PRL}-E F I \alpha(I 0: I)$ reporter vectors. Twenty-four hours after microinjection, the firefly and Renilla luciferase activity was measured using the Dual-Luciferase Reporter Assay System. The results are presented as the Renilla luciferase activity (A, B) or as the normalized luciferase activity (firefly/Renilla) (C). Each bar represents the mean \pm S.E. of ten replicate samples and the data are representative of three independent experiments. The asterisk denotes statistically significant differences between the indicated samples. 


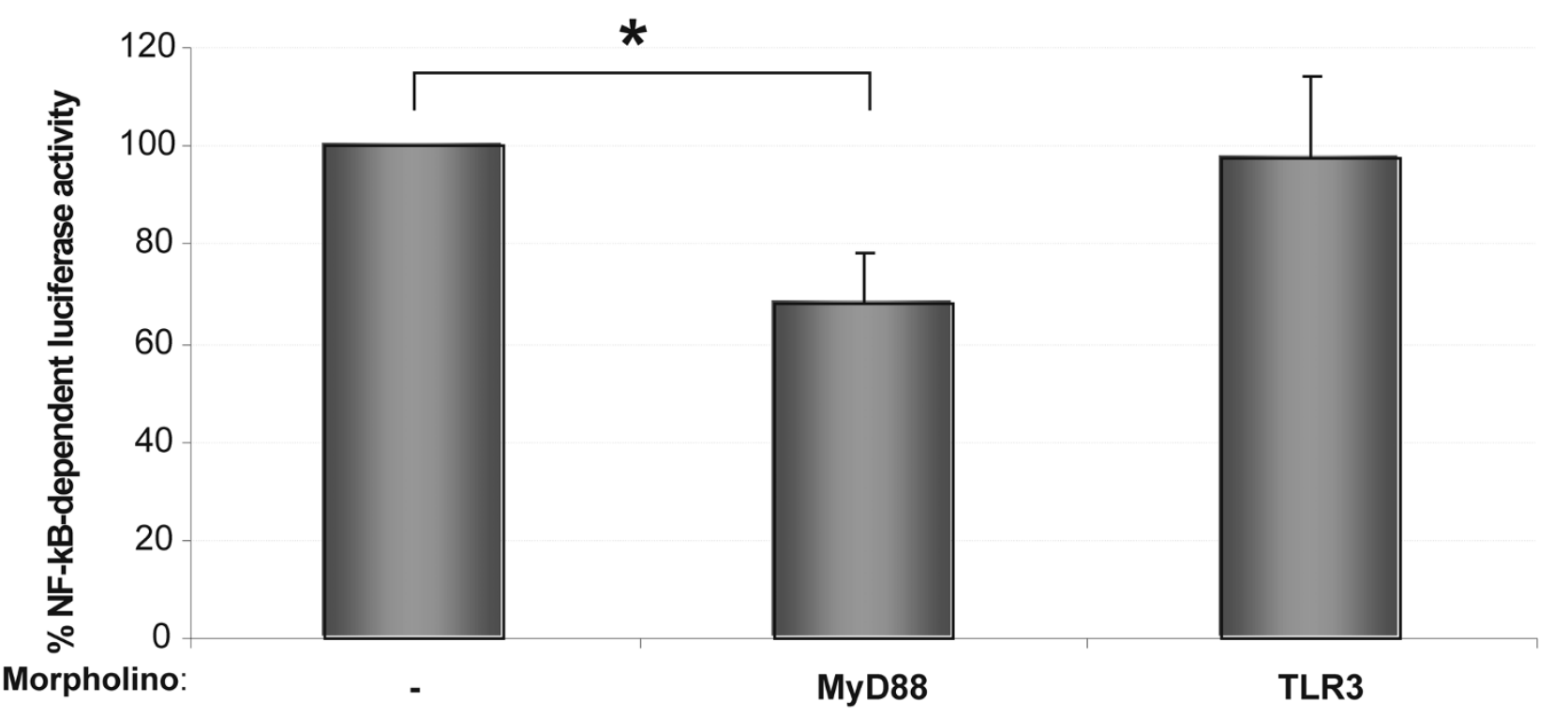

Figure 3

An example of the usefulness of MO-gene mediated knockdown in combination with the dual-luciferase assay for the analysis of the NF- $\kappa$ B signaling pathway. Zebrafish one to eight-cell embryos were microinjected with $6.5 \mathrm{ng}$ VaDNA together with the firefly and Renilla reporter vectors as indicated in Legend to Figure 2 alone or in combination with 4 $\mathrm{ng}$ of the indicated morpholinos. Twenty-four hours after microinjection, activation of the NF- $\mathrm{KB}$ activation was measured using the Dual-Luciferase Reporter Assay System. The results are expressed as normalized luciferase activity relative to control embryos not injected with MOs. Each bar represents the mean \pm S.E. of ten replicate samples and the data are representative of three independent experiments. The asterisk denotes statistically significant differences between the indicated samples.

example, the adaptive immune response can not be studied with the assay since it develops after several weeks. On the other hand, we have found that normalization is absolutely required for the elimination of experimental variations. As we have found that the Renilla luciferase plasmid used for normalization can be induced by external stimuli, the choice of the normalization plasmid is critical. Thus, the CMV immediate-early promoter, which is commonly used for normalization in both in vitro and in vivo studies, is significantly induced by external stimuli such as endotoxin (LPS) and genomic DNA from bacteria, as previously reported in cell lines with LPS, cytokines and phorbol esters [12]. However, this limitation could be easily overcome using other commercial Renilla luciferase reporter vectors, such as those driven by the herpes simplex virus TK promoter (pRL-TK) or the early SV40 enhancer/promoter region (pRL-SV40).

\section{Conclusion}

We have developed a rapid and sensitive assay based on the classical dual-luciferase reporter technique which can be used as a new tool to characterize the minimum pro- moter region of a gene and the in vivo response of inducible promoters to different stimuli as well as in high throughput screening experiments. The flexibility of this assay is demonstrated by induction of the NF- $\kappa \mathrm{B}$-dependent promoters using simultaneous microinjection of different PAMPs as well as with the use of MO-gene mediated knockdown.

\section{Methods \\ Reagents}

- Firefly (Photinus pyralis) luciferase reporter plasmids (Table 1).

- Sea pansy (Renilla reniformis) reporter plasmids from Promega: pRL-CMV (Cat.\# E2261), pRL-TK (Cat.\# E2241) and/or pRL-SV40 (Cat.\# E2231) (Table 1).

- Adult zebrafish.

- Egg water (60 mg/l Ocean Salt, $0.45 \mathrm{mM} \mathrm{NaHCO}_{3}$ $0.0375 \mathrm{mM} \mathrm{CaCO}_{3}, 0.05 \%$ Methylene Blue) 
Table I: Reporter plasmids used in this study

\begin{tabular}{|c|c|c|}
\hline Plasmid name & Purpose & Relevant features \\
\hline pEGFPLuc & $\begin{array}{l}\text { Positive control for assaying the effectiveness } \\
\text { of transfection }\end{array}$ & $\begin{array}{l}\text { Kanamycin/neomycin marker. This reporter plasmid encodes } \\
\text { a fusion of eGFP and luciferase from the firefly Photinus pyralis } \\
\text { driven by the human CMV immediate early promoter } \\
\text { (Clontech, Cat.\# 6169-I). }\end{array}$ \\
\hline plessEGFPLuc & Negative control & $\begin{array}{l}\text { Kanamycin/neomycin marker. This vector was created by } \\
\text { removing the CMV promoter of pEGFPLuc with the } \\
\text { restriction enzymes Asel and Nhel, followed by blunting of } \\
5 \text { '-cohesive ends and autoligation. }\end{array}$ \\
\hline zfpTERT(I/3 Kb)-EGFPLuc & Determination of the zfTERT promoter activity & $\begin{array}{l}\text { Kanamycin marker. This vector was created by replacing the } \\
\text { CMV promoter of pEGFPLuc with a I or } 3 \mathrm{~Kb} \text {-fragment of } \\
\text { the zebrafish telomerase promoter region. }\end{array}$ \\
\hline pNF-kB::Luc & Assessment of NF- $\kappa B$ activation & $\begin{array}{l}\text { Ampicillin marker. This vector carries a the cDNA encoding } \\
\text { the firefly (P. pyralis) luciferase gene placed under the control } \\
\text { of three synthetic copies of the } \kappa B \text { consensus of the } \\
\text { immunoglobulin } \kappa \text {-chain promoter cloned in the BamHI site } \\
\text { located upstream of the conalbumin transcription start site } \\
\text { [19]. }\end{array}$ \\
\hline pRL-CMV, pRL-TK and pRL-SV40 & Normalization & $\begin{array}{l}\text { Ampicillin marker. The pRL vectors contain the cDNA } \\
\text { encoding Renilla luciferase cloned from the anthozoan } \\
\text { coelenterate Renilla reniformis (sea pansy). Three different } \\
\text { promoter configurations are available; CMV, TK and SV40. }\end{array}$ \\
\hline $\mathrm{PRL}-\mathrm{EFI} \alpha$ & Normalization & $\begin{array}{l}\text { Ampicillin marker. This vector was obtained by inserting the } \\
\text { EFI } \alpha \text { promoter in the pRL-null vector (Promega, Cat. \# } \\
\text { E227I). }\end{array}$ \\
\hline
\end{tabular}

Note: pEGFPLuc has been discontinued and is no longer available from Clontech; it can be obtained from the authors on request. Full sequences and maps can be found on the Clontech and Promega websites.

- Agarose-modified Petri dish as described in the Zebrafish book http://zfin.org/zf_info/zfbook/chapt5/ 5.8.html.

- Phenol Red Solution (0.5\% in PBS, Sigma-Aldrich).

- Buffer Tango 10× (Fermentas).

- Morpholinos $1 \mathrm{mM}$ stock solution in distilled water (Gene Tools, LLC).

MO-Myd88: 5'-TAGCAAAACCTCTGTTATCCAGCGA-3' [13]

\section{MO-TLR3: 5'-GTAAAAACATACCTTTAAGAGAGAG-3'}

- EcLPS: LPS from Escherichia coli strains 0111:B4 (Cat.\# L4391) or 055:B5 (Cat.\# L6529) from Sigma-Aldrich.

- LPS from E. coli strains 0111:B4 conjugated with FITC (Cat.\# F3625).

- VaDNA: phenol-extracted genomic DNA from Vibrio anguillarum.

- Dual-Luciferase Reporter Assay System (Promega, Cat.\# E1910).
- Phosphate-buffered saline (PBS).

\section{Equipment}

- Air incubator set at $28.5^{\circ} \mathrm{C}$ (Memmert).

- Curved-tip forceps.

- Straight-tip forceps.

- Puller (PC-10, Narishige).

- Glass Capillaries with filament (GD-1, Narishige).

- Microloader tips (0.5-10 $\mu$ l, Eppendorf).

- Microinjector (IM300, Narishige).

- Stereomicroscope (MZ6, Leica).

- Pellet pestle, disposable (Sigma-Aldrich): Cordless motor (Cat.\# Z359971) and blue polypropylene (autoclavable) (Cat.\# Z359947).

- Luminometer Optocomp I (MGM Instruments).

- Epifluorescence Lumar V12 stereomicroscope equipped with a digital camera (AxioCam MRm) (Zeiss). 


\section{Procedure}

\section{Microinjection}

1- Prepare the microinjection mix containing $20 \mathrm{ng} / \mu \mathrm{l}$ of firefly luciferase and $2 \mathrm{ng} / \mu \mathrm{l}$ Renilla reporter plasmids. Add Buffer Tango $10 \times$ to a final concentration of $0.5 \times$, and phenol red solution to a final concentration of $0.05 \%$. When injecting morpholinos, they should be prepared to a final concentration of $1-10 \mu \mathrm{M}$.

CAUTION! When microinjecting exogenous molecules, such as PAMPs or drugs, check different Renilla reporter plasmids and select those with consistent expression.

2- Immediately after spawning, collect fertilized egg with a Pasteur pipette and place them in egg water on an agarose-modified Petri dish be means of the forceps.
CRITICAL STEP It is very important to microinject the zebrafish embryos at early developmental stages (from one- to eight-cells) to ensure that the cytoplasmic flows introduce DNA into the cell (Fig. 4)

3- Load glass capillaries with 1-5 $\mu$ l of microinjection mix by using a $0.5-10-\mu l$ microloader tip.

4- Put the Petri dish with the fertilized eggs under a stereomicroscope at $40 \times$ magnifications and place the loaded needle toward the yolk sac, close to the embryo cell. By using the microinjector, insert the tip of the needle into the yolk and inject a $4 \mathrm{nl}$ drop by setting the proper pressure (50-60 Psi) and time (10-100 ms).

5- Incubate the injected embryos for $24-48 \mathrm{~h}$ at $28.5^{\circ} \mathrm{C}$ in egg water.

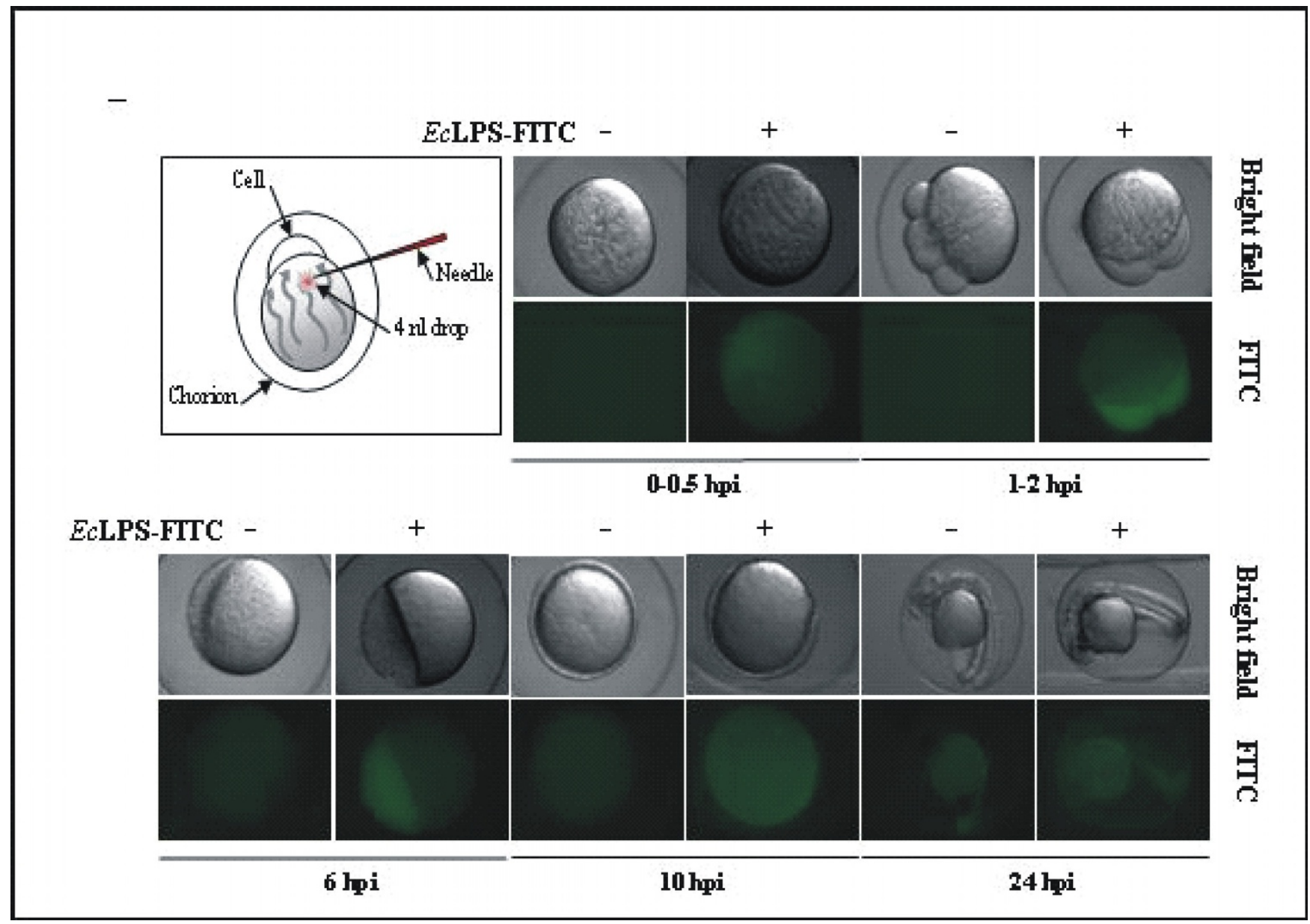

Figure 4

Molecules microinjected in the yolk sac are rapidly delivered into the embryo. (A) Schematic representation of the site of injection in one-cell zebrafish embryo. (B) Visualization of FITC labelled EcLPS upon microinjection into the yolk sac. Embryos were microinjected with $3.5 \mathrm{ng}$ LPS from E. coli strains $0 \mathrm{III}$ :B4 conjugated with FITC and examined at the indicated times with a LUMAR stereomicroscope. hpi, hours post-injection. 
Quantitative evaluation of the response with the Dual-Luciferase Reporter Assay System

6- The next day, collect live injected embryos and put three of them in a $1.5 \mathrm{ml}$ microcentrifuge tube.

7- Remove the egg water, wash the embryos with PBS and remove it completely.

CAUTION! Take care during the wash because the eggs may break.

8- Incubate the embryos with $50 \mu \mathrm{l}$ of passive lysis buffer (PLB) $1 \times$ for $30 \mathrm{~min}$ at room temperature, shaking at 150 rpm.

9- After incubation, homogenize the embryos with the pellet pestle.

CRITICAL STEP From this point onwards, protect samples from light.

10- Spin the embryo extracts for $3 \mathrm{~min}$ at $13,000 \mathrm{rpm}$ to remove cellular debris.

11- Measure firefly and Renilla luciferase activities according to the manufacturer.

\section{- Timing}

- Step 1: $30 \mathrm{~min}$. Preparation of microinjection mix.

- Step 2: $10 \mathrm{~min}$. Preparation for injection of 100 zebrafish embryos.

- Steps 3-5: $15 \mathrm{~min}$. Microinjection of 100 zebrafish embryos.

- Steps 6-11: 2 h. Quantitative evaluation of the response of 100 zebrafish embryos with the Dual-Luciferase Reporter Assay System.

\section{Authors' contributions}

F.A-P., M.L.C and V.M. designed the research, analyzed the data and wrote the paper; F.A-P. performed the research. All authors read and approved the final manuscript.

\section{Acknowledgements}

We thank E.M. García-Navarro for excellent technical assistance and Dr. R Hay for the NF-KB::Luc reporter construct. This work was supported by the Spanish Ministry of Education and Science (grant BIO2005-05078 to V.M.), the Spanish Ministry of Health (grant PI060369 to M.L.C.) and the University of Murcia (fellowships to F.A.-P.)

\section{References}

I. Patton EE, Zon LI: The art and design of genetic screens: zebrafish. Nat Rev Genet 200I, 2:956-966.

2. Nicoli S, Presta M: The zebrafish/tumor xenograft angiogenesis assay. Nat Protoc 2007, 2:2918-2923.

3. Pyati UJ, Look AT, Hammerschmidt M: Zebrafish as a powerful vertebrate model system for in vivo studies of cell death. Sem Cancer Biol 2007, 17:154-165.

4. Ekker SC: Nonconventional antisense in zebrafish for functional genomics applications. Methods Cell Biol 2004, 77:12 I- I36.

5. Ekker SC, Larson JD: Morphant technology in novel developmental systems. Genesis 200I, 30:89-93.

6. Nasevicius A, Ekker SC: Effective targeted gene "knockdown" in zebrafish. Nat Genet 2000, 26:216-220.

7. Sumanas S, Larson JD: Morpholino phosphorodiamidate oligonucleotides in zebrafish: a recipe for functional genomics? Brief Functional Genomics Proteomics 2002, I:239-256.

8. Kamachi $\mathrm{Y}$, Okuda $\mathrm{Y}$, Kondoh $\mathrm{H}$ : Quantitative assessment of knockdown efficiency of morpholino antisense oligonucleotides in zebrafish embryos using a luciferase assay. Genesis 2007, 46:1-7.

9. Detrich HW 3rd: Fluorescent proteins in zebrafish cell and developmental biology. Methods Cell Biol 2008, 85:2 I9-24I.

10. Blasco MA: Telomere length, stem cells and aging. Nat Chem Biol 2007, 3:640-649.

II. Kawai T, Akira S: Signaling to NF- $\kappa B$ by Toll-like receptors. Trends Mol Med 2007, 13:460-469.

12. Ramanathan M, Haskó G, Leibovich SJ: Analysis of signal transduction pathways in macrofages using expression vectors with CMV promoters: a cautionary tale. Inflammation 2005, 29:94-102.

13. Sar AM van der, Stockhammer OW, Laan $C$ van der, Spaink HP, Bitter W, Meijer AH: MyD88 innate immune function in a zebrafish embryo infection model. Infect Immun 2006, 74:2436-244I.

14. O'neill LA, Bowie AG: The family of five: TIR-domain-containing adaptors in Toll-like receptor signaling. Nat Rev Immunol 2007, 7:353-364

15. Vercammen E, Staal J, Beyaert R: Sensing of viral infection and activation of innate immunity by toll-like receptor 3 . Clin Microbiol Rev 2008, 21:13-25.

16. Zon LI, Peterson R: In vivo drug discovery in the zebrafish. Nat Rev Drug Discov 2005, 41 :35-44.

17. Langheririch U: Zebrafish: a new model on the pharmaceutical catwalk. BioEssays 2003, 25:904-912.

18. Murphey RD, Zon LI: Small molecule screening in the zebrafish. Methods 2006, 39:255-26I.

19. Arenzana-Seisdedos F, Fernandez B, Dominguez I, Jacqué JM, Thomas D, Diaz-Meco MT, Moscat J, Virelizier JL: Phosphatidylcholine hydrolysis activates NF-kappa B and increases human immunodeficiency virus replication in human monocytes and $\mathbf{T}$ lymphocytes. J Virol 1993, 67:6596-6604.

Publish with Bio Med Central and every scientist can read your work free of charge

"BioMed Central will be the most significant development for disseminating the results of biomedical research in our lifetime. "

Sir Paul Nurse, Cancer Research UK

Your research papers will be:

- available free of charge to the entire biomedical community

- peer reviewed and published immediately upon acceptance

- cited in PubMed and archived on PubMed Central

- yours - you keep the copyright

Submit your manuscript here:

http://www.biomedcentral.com/info/publishing_adv.asp
BioMedcentral 